\title{
Study of coherence of temperature variations in the tropopause associated with earthquakes
}

\author{
Leonid Sverdlik ${ }^{1, *}$, Sanjar Imashev ${ }^{1}$ \\ ${ }^{1}$ Research Station of the Russian Academy of Sciences in Bishkek, Kyrgyzstan
}

\begin{abstract}
The paper presents retrospective analysis of satellite data of the upper troposphere / lower stratosphere over the epicentral area of the destructive earthquake of $\mathrm{M}=6.7$, occurred in Tien-Shan territory. We established a well-defined temporal and spatial coherence between temperature perturbations and seismic activity. We used wavelet analysis to identify temporal and spectral coherence of temperature variations in a boundary zone of troposphere and stratosphere before the seismic event.
\end{abstract}

\section{Introduction}

Study of pre-seismic atmospheric perturbations performed using ground-based and satellite methods revealed formation of anomalous variations of different geophysical parameters. Thereat, a wide range of physical and chemical processes was identified as short-term precursors of an oncoming strong earthquake $[1,2]$. We considered, in particular, releases (emissions) of gases into the atmosphere, anomalous fluctuations of meteorological parameters, electric field intensity, outgoing long-wave radiation (OLR), as well as VLF and ELF bursts, etc. $[3,4]$.

We used temperature as a parameter changes of which were indications of atmospheric perturbations because it plays a key role in formation of conditions of running of majority of processes and vertical atmosphere structure. While temperature changes are of complicated nature, areas where change of vertical temperature gradient sign takes place are most sensitive to various perturbing factors and atmospheric waves activity [5]. Our investigation is based on analysis of temperature temporal changes at isobaric levels in the upper troposphere and lower stratosphere (UTLS) [6]. Characteristic peculiarities of temperature changes in the atmospheric regions separated by the tropopause allowed investigating temporal and frequency coherence effects preceding major earthquakes [7]

This paper presents study of peculiarities of short-period temperature variations in UTLS over the epicentral area of an earthquake of $M=6.7$. Dynamic processes in the atmospheric layers and perturbations that are results of interaction between atmospheric layers and lithosphere during periods of seismic activity were analyzed on the basis of remote sensing data.

\footnotetext{
*Corresponding author: 1.sverdlik@mail.ru
} 


\section{Seismic and temperature measurements data}

The Nura destructive earthquake of $\mathrm{M}=6.7$ was registered in southern Kyrgyzstan $\left(39.53{ }^{\circ} \mathrm{N}\right.$; $73.82^{\circ} \mathrm{E}$ ) on October 5, 2008 (15:52:50 UTC). The focal depth was $\sim 27 \mathrm{~km}$ [8] and about 50 aftershocks with magnitudes varying from 3.0 to 5.9 occurred within 24 hours (Fig. 1a). Fig. $1 \mathrm{~b}$ shows distribution of magnitudes and number of seismic events with $\mathrm{M} \geq 4.0$ in September-October, 2008.
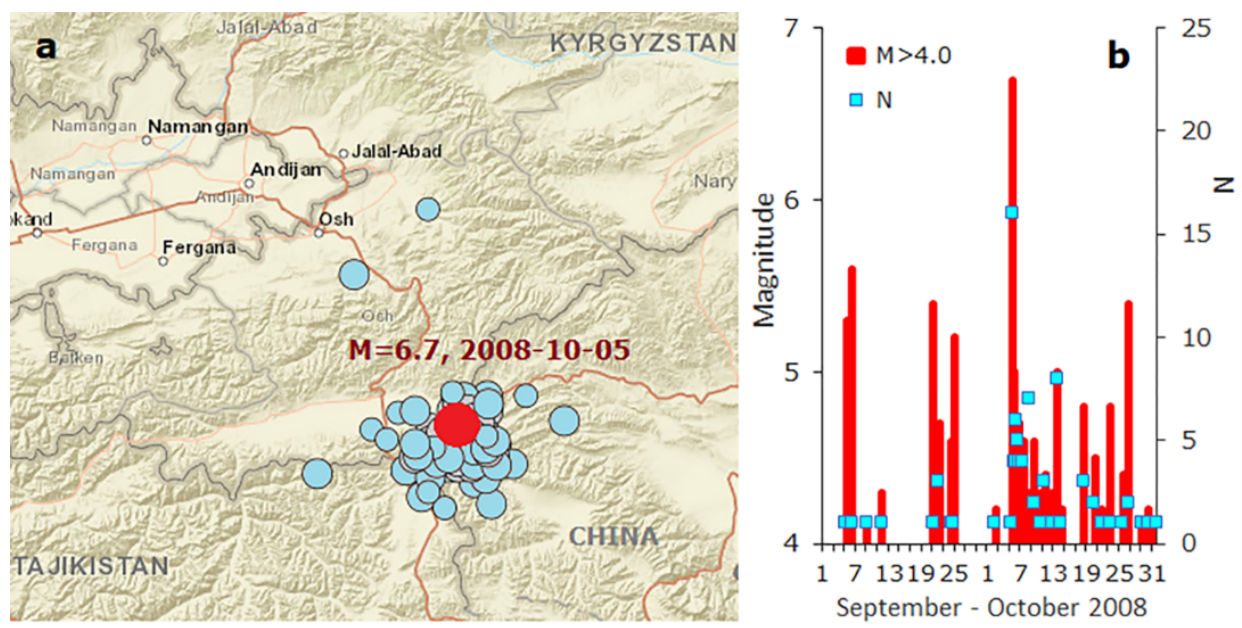

Fig. 1. Aftershock field $M=6.7$ (05.10.2008) (a) and distribution of magnitudes and number of seismic events (N) with $M \geq 4.0$ in September-October, 2008, (b)

Analysis of vertical and temporal variations of atmospheric temperature $(\mathrm{T})$ was performed using satellite measurement data. Temperature data of MERRA-2 global reanalysis system [9] are based on satellite observations processed on a global model and represent synthesized temperature values at standard isobaric levels from 450 to $70 \mathrm{hPa}$ with spatial resolution of $0.5^{\circ} \times 0.625^{\circ}$. We considered a period of August 15 - November 15, 2008 . The temporal discretization was $\Delta \mathrm{t}=3 \mathrm{~h}$, which allowed to trace the process of temperature perturbations formation and dynamics of spectrum variation in UTLS in sufficient details.

\section{Results and Discussion}

\subsection{Temporal and spatial distribution of temperature perturbations before Nura earthquake}

Fig. 2a shows night temperature profiles (00:00 UTC) in the altitude range of 5.0-25.0 km (450-40 hPa) measured several days before the earthquake in Tien-Shan (October 01-04, 2008.). Initial data of satellite measurements of temperature usually do not allow identifying seismic-atmospheric anomalies and setting them apart from perturbations generated by other natural processes. To investigate interrelation between anomalous temperature changes and seismic activity we can apply methods of satellite data processing, such as RST (Robust Satellite Techniques) [2] or modified methods developed from it [6] and based on calculations of normalized temperature anomalies (Fig. 2b) that reflect temperature behavior specifics in the studied region. 

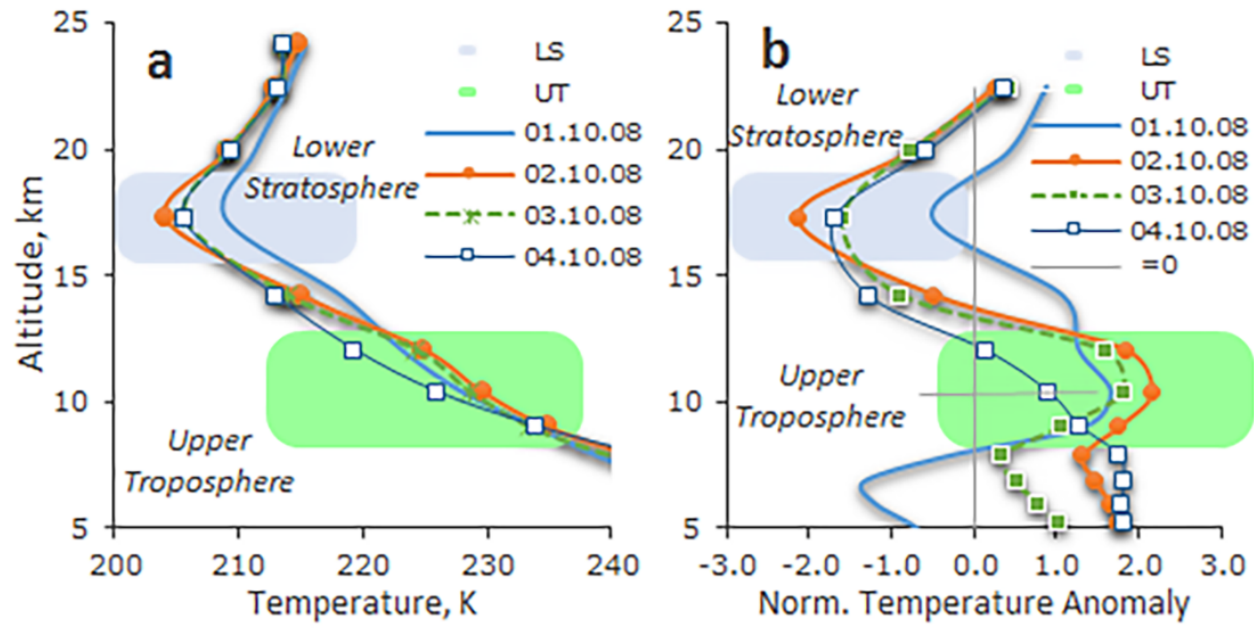

Fig. 2. Vertical temperature (a) and normalized temperature anomalies (b) profiles in the altitude range of 5.0-25.0 km over the epicentral area of the earthquake with $M=6.7$, October 1-4, 2008 (00:00 UTC)

As it follows from Fig. 2 the most intensive antiphase temperature changes occurred at isobaric levels of $200 \mathrm{hPa}(\sim 12 \mathrm{~km})$ in the upper troposphere and $100 \mathrm{hPa}(\sim 17 \mathrm{~km})$ in the lower stratosphere. Time series $\mathrm{T}(\mathrm{t})$ and normalized temperature anomalies in September October 2008 corresponding to this levels are presented in Fig. 3a and Fig. 3b accordingly. Results of temperature anomalies diagnosis using the algorithm described in $[5,6]$ demonstrated that temperature changes in these atmospheric regions occurred in a coherent manner. The well-defined outburst of $\mathrm{D}_{\delta \mathrm{T}}=2.2$, appeared 2 days before the seismic event with $\mathrm{M}=6.7$ (Fig. 3c) indicates a relation with the earthquake preparation period (Fig. 3d).
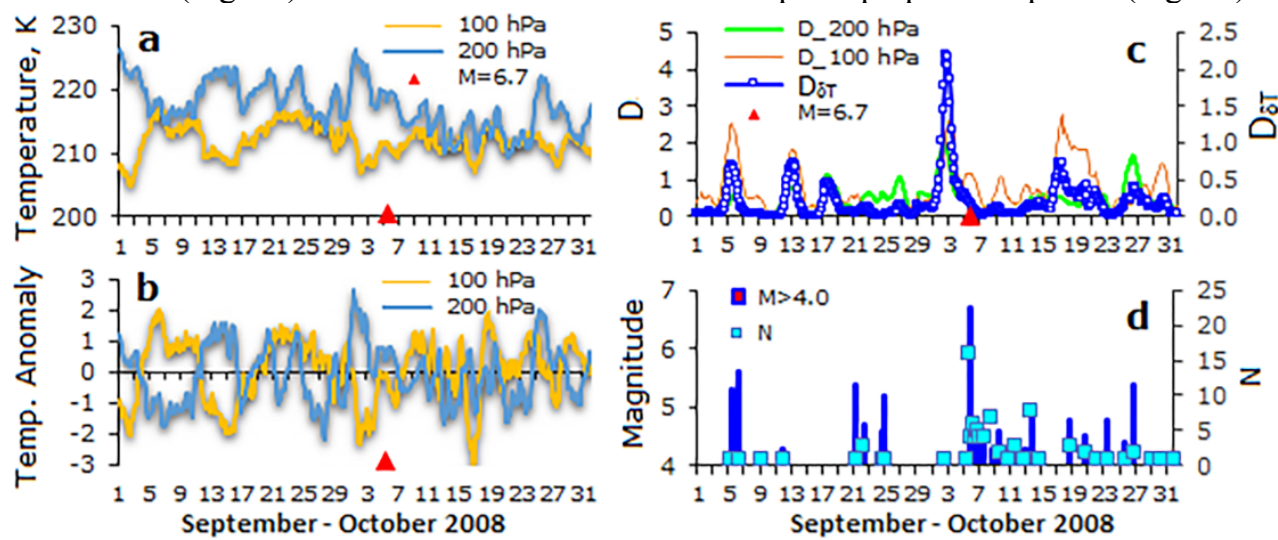

Fig. 3. Temperature (a) and normalized anomalies variations at 200 and $100 \mathrm{hPa}$ levels (b), variations of $D_{\delta \mathrm{T}}$ integral parameter (c) and series of magnitudes and number of earthquakes with $M \geq 4.0$ (d) in September-October, 2008.

$\mathrm{D}_{\delta \mathrm{T}}$ integral parameter allowed to assess spatial extent of the temperature perturbation observed in the tropopause during the period of preparation and occurring of the strong earthquake with $\mathrm{M}=6.7$. Results showed formation of a mesoscale temperature perturbation near the earthquake epicentral area. Fig. 4 presents results of processing of temperature data at isobaric levels of 250 and $100 \mathrm{hPa}$ on October 2, 2008 at 15:00 UTC. Horizontal dimensions of the perturbation were several hundred kilometers (in latitude and longitude) and approximately corresponds to the anomaly detected in the course of previous analysis of 
the seismic event of $\mathrm{M}=7.4$ (December 19, 1992) [7]. High values of $\mathrm{D}_{\delta \mathrm{T}}$ persisted during 1.5 day and maximum of anomaly was observed on October 2-3, 2008, i.e. $\sim 2.5$ days before the seismic event with $M=6.7$. Spatial configuration of a temperature anomaly is usually substantially affected by atmospheric circulation processes. West-east air transfer in the middle latitudes results in distribution of temperature perturbations in an easterly direction.

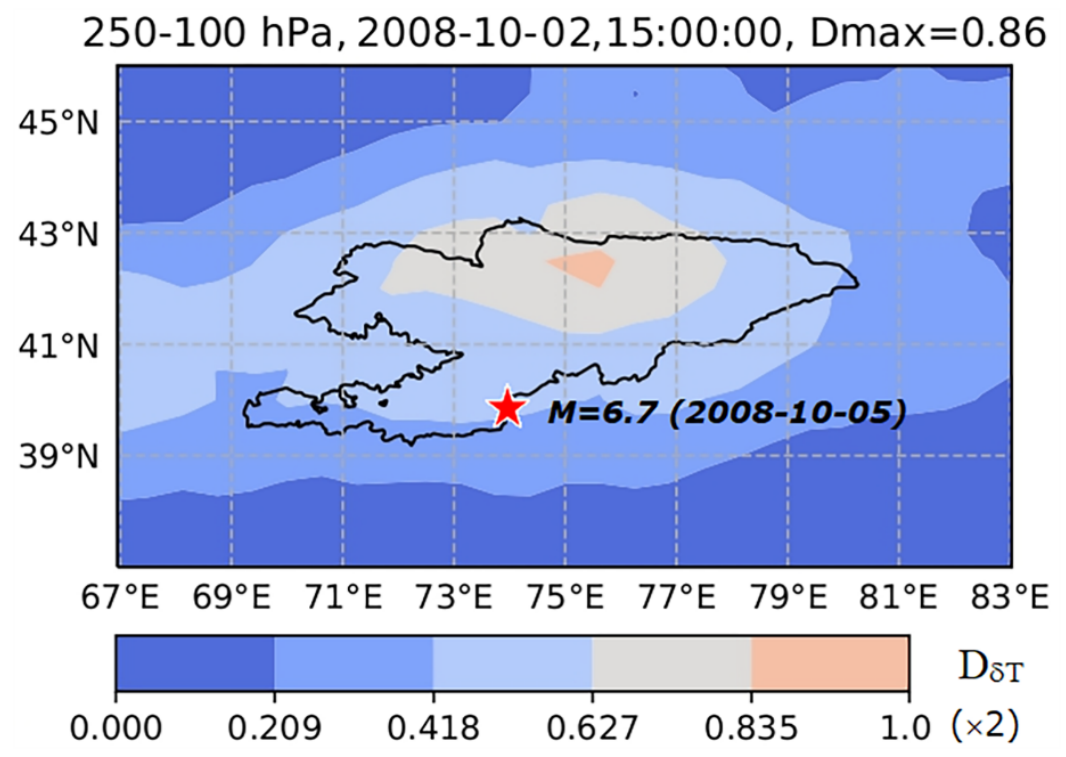

Fig. 4. The spatial distribution of anomalous variation integral parameter $\mathrm{D}_{\delta \mathrm{T}}$ on October 2, 2008 at 15:00 UTC

\subsection{Wavelet Coherency Analysis of temperature variations in the upper troposphere and lower stratosphere}

Study of spectral composition dynamics of the data was performed using continuous wavelet transform. Wavelet spectrograms of temperature time series at 200 and $100 \mathrm{hPa}$ levels (Fig. 5) constructed for periods of 0.125 to 32 days demonstrate change of their frequency properties during August 15 - November 15, 2008.

A characteristic feature of the spectrograms is well-defined intensive oscillations within the range of 8-12 days in the beginning of September $(100 \mathrm{hPa})$ and at the end of October (200 hPa), while $\sim 4-5$ daily periodicities concurrently appearing at both isobaric levels were registered in the spectrum before the Nura earthquake.

We performed calculation of the spectral coherence measure to analyze effects of consistent variability and statistic interrelation between temperature variations in atmosphere layers separated by the tropopause over the epicentral area of the earthquake. Fig. 6 presents the temporal evolution of the squared coherence between temperature variation spectra at 200 and $100 \mathrm{hPa}$ isobaric levels. The diagramm characterizes the correlations that exist between the spectral components in the temperature oscillations in the upper troposphere and lower stratosphere. 

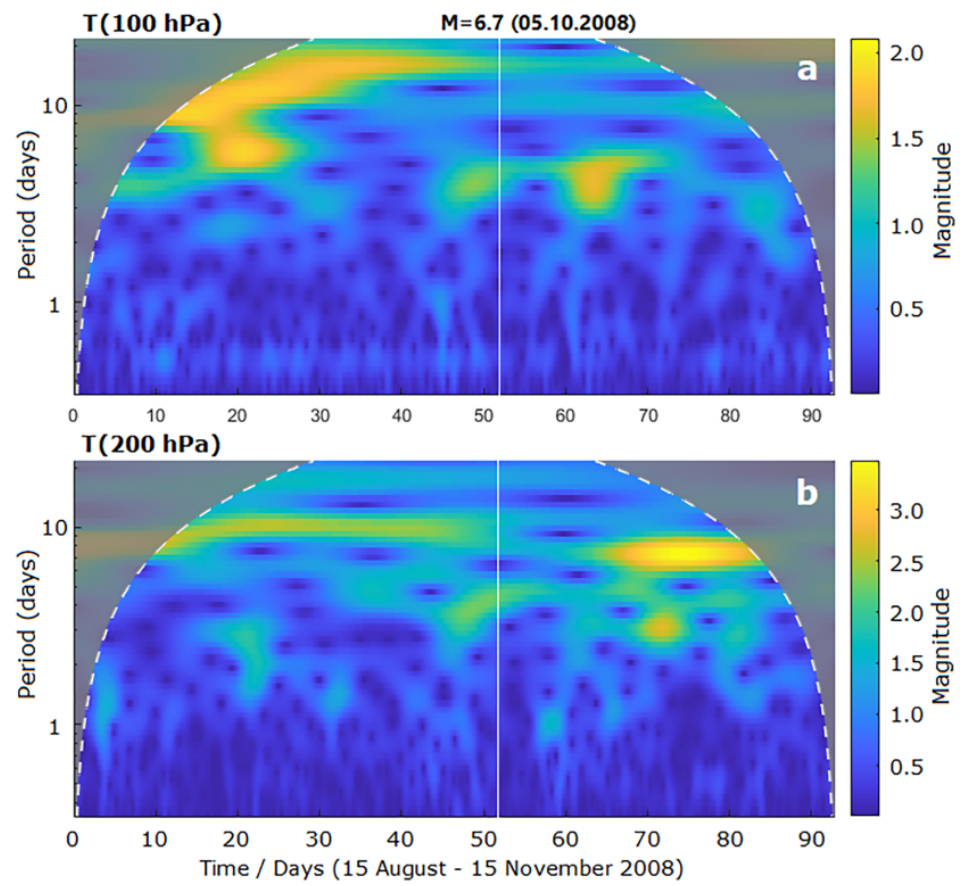

Fig. 5. Temperature variations spectra dynamics at $100 \mathrm{hPa}$ and $200 \mathrm{hPa}$ levels during the period of August 15 to November 15, 2008. The vertical line corresponds to the moment of the earthquake with $\mathrm{M}=6.7$

As we can see, time-localized areas of strong coherence appeared at periods of 3-6 days starting on October 1, 2008. Thereat, virtually there was no enlarging of the coherence area towards long or short periods. Accordingly, the scale range with high coherence coefficients exceeding 0.8 remains relatively stable in time until the moment of the earthquake, that is indicative of consistent running of oscillating processes in the upper troposphere and lower stratosphere. Increasing of coherence values stemmed from anomalous short-period temperature changes. Arrows directions indicate presence of phase change between oscillations $\mathrm{T}(\mathrm{t})$. Therefore, the identified frequency-temporal anomaly is in agreement with obtained results of temperature anomalies analysis based on, calculations of integral parameters (Fig. 3) [6,7].

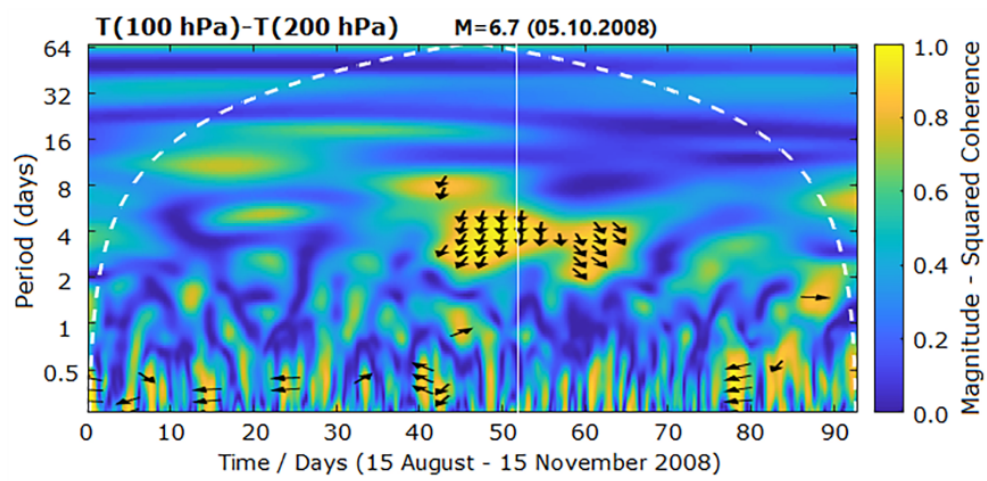

Fig. 6. Evolution of the wavelet coherent coefficients between the temperature variation spectra at isobaric levels of 200 and $100 \mathrm{hPa}$ (August 15 - November 15, 2008). Coherence magnitude and relative phase are denoted by color and orientation of the arrows, respectively 
Presented features of temperature coherent are in agreement with results of our previous investigations $[7,10]$ where we detected coincidence of oscillations frequencies concurrently appearing in temperature variation spectra in the upper troposphere and lower stratosphere. Coherent temperature variations before the Nura earthquake $(M=6.7$, October 5, 2008) and Suusamyr earthquake (M=7.3, August 19, 1992) can be an indication of pre-seismic perturbations in the tropopause region.

Wave processes are typical mechanism of lithospheric-atmospheric interrelations [3, 11]. A probable reason for formation of anomalous temperature perturbations preceding major earthquakes can be excitement of intense long-period seismic-gravitational oscillations and synchronous and spectrum-identical pulsations that results in UTLS temperature perturbations near the earthquake epicenter [12].

\section{Conclusions}

Analysis of remote sensing data showed that anomalous temperature changes in the upper troposphere and lower stratosphere were observed over the epicentral area of the strong earthquake with $M=6.7$. Study of periodicities revealed the effects of coherent temperature behavior in UTLS in the interval of periods varying from 3 to 6 days preceding activation of the seismic regime in Tien-Shan territory.

The presented spatial-temporal distributions of anomalous temperature perturbations point at probable relation to the seismic process.

The obtained results demonstrate prospectivity of application of this method for identification of pre-seismic anomalies in the atmosphere, as well as the necessity of further study of the discovered effect of coherence of temperature variations in the UTLS.

The author is grateful to Giovanni team of NASA GES DISC for free access to satellite measurement data and modeling results.

The study is partially performed within the framework of the state task of the Federal State Budgetary Institution of Science, Research Station of Russian Academy of Sciences in Bishkek (theme No. AAAA-A19-119020190064-9).

\section{References}

1. Z-H. Jiao, J. Zhao, X. Shan, Nat. Hazards Earth Syst. Sci. 18, 1013 (2018).

2. V. Tramutoli, R. Corrado, C. Filizzola, N. Genzano, M. Lisi, N. Pergola, Bollettino di Geofisica Teorica ed Applicata. 56. 2. 167 (2015).

3. C. Oikonomou, H. Haralambous, S. Pulinets, A. Khadka, S.R. Paudel, V. Barta, B. Muslim, K. Kourtidis, A. Karagioras, S. Inyurt, Geosciences. 11, 16, 28 (2021).

4. S. Sasmal, S. Chowdhury, S. Kundu, D.Z. Politis, S.M. Potirakis, G. Balasis, M. Hayakawa, S.K. Chakrabarti, Atmosphere, 12, 1059 (2021).

5. L.G. Sverdlik, S.A. Imashev, J. Sib. Fed. Univ. Eng. Technol. 11, 956 (2018).

6. L.G. Sverdlik, S.A. Imashev, MAUSAM. 71, 481 (2020).

7. L. Sverdlik, S. Imashev. E3S Web of Conferences. 223, 03015, (2020).

8. URL: https://earthquake.usgs.gov/earthquakes/search/

9. URL: https://disc.gsfc.nasa.gov/datasets/

10. L.G. Sverdlik, Sovremennye problemy distantsionnogo zondirovaniya Zemli iz kosmosa. 18, 3, 141 (2021).

11. V. Kashkin, L. Sverdlik, R. Odintsov, T. Rubleva, K. Simonov, A. Romanov, S. Imashev, E3S Web of Conferences. 149, 03011 (2020).

12. E.M. Linkov, L.N. Petrova, K.Ts. Osipov, Doklady AN SSSR. 313, 1095 (1990). 